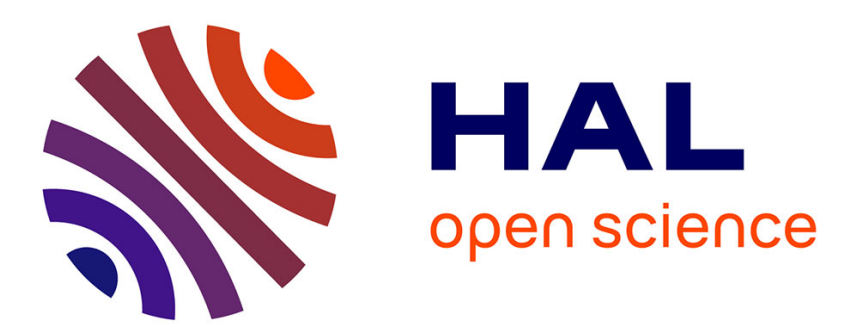

\title{
Incorporation of elastomer into poly(ether ether ketone): an attempt to improve the damping factor
}

Thibault Parpaite, Franck Sosson, Rodolphe Sonnier, Laurent Clerc, Anne Bergeret

\section{- To cite this version:}

Thibault Parpaite, Franck Sosson, Rodolphe Sonnier, Laurent Clerc, Anne Bergeret. Incorporation of elastomer into poly(ether ether ketone): an attempt to improve the damping factor. High Performance Polymers, 2014, 26 (8), pp.986-996. 10.1177/0954008314536592 . hal-02914578

\section{HAL Id: hal-02914578 https://hal.mines-ales.fr/hal-02914578}

Submitted on 27 May 2021

HAL is a multi-disciplinary open access archive for the deposit and dissemination of scientific research documents, whether they are published or not. The documents may come from teaching and research institutions in France or abroad, or from public or private research centers.
L'archive ouverte pluridisciplinaire HAL, est destinée au dépôt et à la diffusion de documents scientifiques de niveau recherche, publiés ou non, émanant des établissements d'enseignement et de recherche français ou étrangers, des laboratoires publics ou privés. 


\title{
Incorporation of elastomer into poly(ether ether ketone): an attempt to improve the damping factor
}

\author{
Thibault Parpaite ${ }^{1,2}$, Franck Sosson ${ }^{2}$, Rodolphe Sonnier', \\ Laurent Clerc' and Anne Bergeret'
}

\begin{abstract}
The incorporation of an elastomer phase into a poly(ether ether ketone) (PEEK) matrix was carried out using two different processing methods (melt blending (MB) and dry blending) to improve the damping factor (tan $\delta$ ) of the composite with a minimal change in the PEEK stiffness. A cross-linked fluoroelastomer (CFE) was carefully chosen according to its high glass transition temperature $\left(T_{\alpha}\right)$, high thermal stability and high modulus. The blends were characterized by scanning electron microscopy (SEM), dynamic mechanical thermal analysis (DMTA), modified Oberst test, flexural test and pyrolysis combustion flow calorimeter. According to SEM micrographs, an original well-dispersed PEEK-elastomer composite was obtained. The $\tan \delta$ of the materials was evaluated using DMTA and modified Oberst test. Both techniques indicate that the incorporation of 5-20 wt\% of CFE fine powders only slightly increased the tan $\delta$ of the material. Moreover, a decrease in flexural modulus and thermal stability of the blends was detected when there was an increase in the CFE content. Even if the properties are not yet significantly improved, it was well ascribed that the MB method was suitable to mix elastomer particles within a PEEK matrix. Poor interfacial adhesion has been identified as the main key parameter, which should be improved in further work.
\end{abstract}

\section{Keywords}

PEEK, elastomer, damping factor, DMTA, Oberst test

\section{Introduction}

Poly(ether ether ketone) (PEEK) is used in aeronautics due to its outstanding properties, such as high stiffness, high resistance to solvents and excellent thermal stability. Its low density compared to metals enables it to be used as an alternative to aluminium in some applications.

Nevertheless, the low $\tan \delta$ of PEEK is limiting its widespread usage. Indeed, for aeronautic applications, this property is of utmost importance to reduce noise emissions in the aircraft cabin generated by the vibration of the structure during the flight. The damping properties of structures can be considerably improved using the viscoelastic shear damping mechanism. ${ }^{1-7}$ For example, a combination of elastic elements separated by layers of a viscoelastic damping material constitutes sandwichstructured composite. When structural composites with constrained viscoelastic layers undergo flexural vibrations, the layers of viscoelastic damping material are subjected to cyclic shear strains, which cause energy of mechanical motion to be converted into thermal energy.
Because of this energy conversion process, the treated structures can exhibit high damping performances. SMAC Company has developed a broad range of products (SMACSONIC $^{\circledR}$, France) to fulfil the various aspects of frequency, temperature and environment. ${ }^{8}$

Another possibility to improve the damping properties of brittle polymers is to incorporate an elastomeric phase directly into it. An abundant literature is available about such a method, in particular, with the objective of an improvement in impact strength (at high deformation levels). ${ }^{9}$ In some cases, elastomers were already incorporated as crosslinked particles. As an example, ground tyre rubber (GTR)

\footnotetext{
'Ecole des Mines d'Alès, Centre des Matériaux des Mines d'Alès, Alès Cedex, France

${ }^{2}$ SMAC, La Garde Cedex, France
}

\section{Corresponding author:}

Rodolphe Sonnier, Ecole des Mines d'Alès, Centre des Matériaux des Mines d'Alès, 6 avenue de Clavières, Alès Cedex 30319, France.

Email: rodolphe.sonnier@mines-ales.fr 
particles (with particle size $>100 \mu \mathrm{m}$ ) were incorporated into different thermoplastic matrices (polyethylene, PE; polypropylene; or polyamide). ${ }^{10-12}$ Despite some compatibilizing treatments, mechanical properties at high deformation levels fall drastically with the increase in GTR content. One of the main reasons is decohesion at the interface between the rubber particles and the matrix. In the present work, mechanical properties are studied at low deformation levels (elastic field) so that decohesion is not believed to occur.

Already some patents and industrial applications exhibit PEEK-elastomer sandwich composite. ${ }^{13-15}$ But to the best of our knowledge, this is the first report on hot melt PEEK-elastomer compound in the open literature. This may be due to the fact that high melting point of PEEK, which is close to (or over to) the degradation temperature of the majority of elastomers. Mixing process of such a compound is not a usual method and that is the main technical challenge of this article.

In relation to this aspect, three objectives are defined for this article:

- The first objective is focused on the grinding of small particles of elastomer with micrometric size. Elastomer particle size is often high (several hundreds of microns at least), while it is generally considered that the particle's size should be less than few microns to allow an improvement of the viscoelastic properties.

- The second objective deals with the incorporation of an elastomer phase into a PEEK matrix without degrading the overall material during hightemperature processing.

- The last objective is to increase the $\tan \delta$ of the PEEK without decreasing its original stiffness. The use of a cross-linked structure for the elastomer would minimize the entanglement of rubber macromolecules with PEEK matrix and then decrease the cohesion between both materials. Nevertheless, at low deformation levels (in the linear viscoelastic field of the material), decohesion should not appear and the elastomer particles may improve the damping properties of the PEEK.

The most commonly used test for the measurement of the $\tan \delta$ is dynamic mechanical thermal analysis (DMTA), which analyses the viscoelastic properties of organic material like rubber-filled carbon black. ${ }^{16-20}$ In addition, a specific vibration test derived from a commonly used test developed for laminated glasses was performed. ${ }^{21}$ This method is a modification of an Oberst beam test described in the ASTM E756 standard. ${ }^{22}$ The specimen is excited at its centre by an electrodynamic shaker as a free-free beam, which has the same behaviour as a cantilever beam of half the length. The modal loss factor of the composite beam is determined using half power bandwidth method for each flexural mode.

In relation with this aspect, another objective of this article is to follow the evolution of $\tan \delta$ obtained using the following two techniques: DMTA and modified Oberst test.

\section{Experimental}

\section{Materials}

VESTAKEEP ${ }^{\circledR}$ PEEK from EVONIK Company (Germany) is a high-viscosity product (commercial grade). The glass transition temperature $\left(T_{\alpha}\right)$ and melting temperature are $143^{\circ} \mathrm{C}$ and $344^{\circ} \mathrm{C}$, respectively (Perkin-Elmer, Waltham, Massachusetts, USA; Diamond DSC $-10^{\circ} \mathrm{C} \mathrm{min}^{-1}$ - nitrogen flow). According to EVONIK data sheet, the density is 1.3 and the melt volume flow rate is $12 \mathrm{~cm}^{3} 10 \mathrm{~min}^{-1}$ under a load of $5 \mathrm{~kg}$ at $380^{\circ} \mathrm{C}$. According to the ISO 527-1 standard, the value of tensile modulus is $3500 \mathrm{MPa}$.

Three kinds of elastomer are studied in this study. The first one is an uncross-linked copolymer of vinylidene fluoride and hexafluoropropylene (uncross-linked fluoroelastomer, UFE). The second is the same elastomer but cross-linked using peroxide additive (cross-linked fluoroelastomer, CFE). The third elastomer is a cross-linked polydimethylsiloxane (PDMS). Commercial grades could not be discussed in detail for confidential reasons.

\section{Micron-sized grinding}

The control of the particle size of the elastomers was investigated to obtain the smallest particles. Elastomer grinding was performed using a Retsch ZM 200 knife grinder (Germany). Various conditions of grinding were tested. To obtain the smallest particles, elastomer sheets were cut into small parts with the dimension of $2 \mathrm{~mm}^{2}$. Each part was successively incorporated into the grinder at room temperature. The speed of knives was fixed at $6000 \mathrm{r} \mathrm{min}^{-1}$ and the grid size was $0.2 \mathrm{~mm}$. These conditions allow avoiding the thermal degradation of the elastomer during grinding.

\section{PEEK-elastomer composite processing methods}

Two processing methods were considered to prepare the compounds:

- The first one is the melt blending (MB) of the PEEK and the elastomer. The MB was carried out using a Rheomix 3000 p Haake Plasticorder (Saddle Brook, New Jersey, USA) with a tank of $60 \mathrm{~cm}^{3}$ volume. The temperature and the rotor speed were fixed at $370^{\circ} \mathrm{C}$ and $55 \mathrm{r} \mathrm{min}^{-1}$, respectively. PEEK was previously dried at $180^{\circ} \mathrm{C}$ for $2 \mathrm{~h}$ for melting process. After PEEK melting, the elastomer was added and the mixing was stopped 3 min later. Then, the tank 


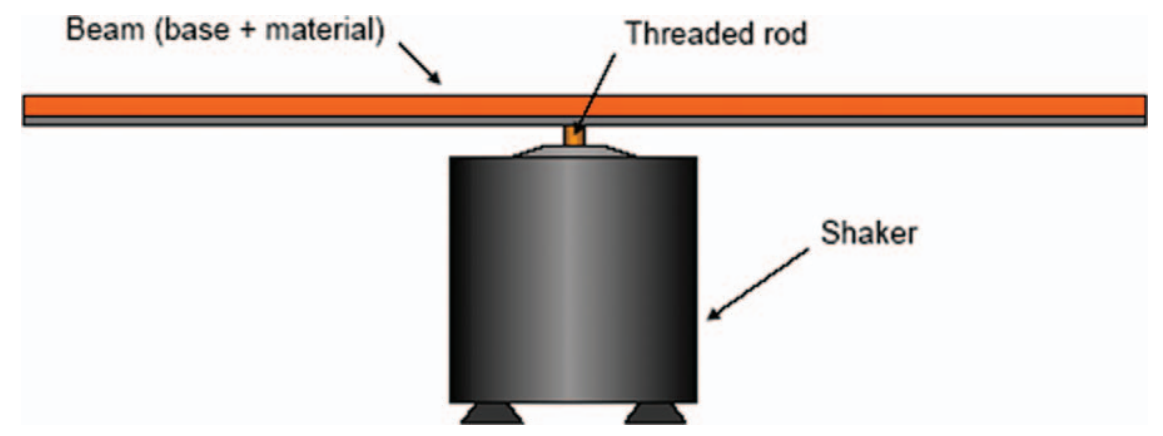

Figure I. Proposed experimental set-up for modified Oberst test.

was filled at $70 \%$ to ensure the best mixing. The elastomer content varied between $2.5 \mathrm{wt} \%$ and 20 wt\%. Resulting PEEK-elastomer blends and pure PEEK were ground in the same conditions as that of elastomers except the grid size that was fixed to $1 \mathrm{~mm}$. Plates were obtained through compression moulding to perform samples for DMTA, flexural and modified Oberst tests. The compression moulding was carried out at $400^{\circ} \mathrm{C}$ for $150 \mathrm{~s}$ with several cycles of pressure (Pinette Emidecau Industries, France). Specimens were released from the mould when the temperature reached $160^{\circ} \mathrm{C}$.

- The second method is the dry blending (DB) of PEEK and elastomer powders using a Rotator Drive STR4 from Stuart Scientific (UK). This method was tested to avoid the first processing step and to limit the degradation of the elastomer. The procedure of mixing was optimized to obtain a homogeneous powder. The compression moulding was performed in the same conditions as previously.

\section{Testing}

After grinding, size distribution of elastomer particles was measured using a Coulter LS 230 laser diffraction particle size analyser (Pasadena, California, USA). The elastomer powder was floated on deionized water for analysis.

Thermogravimetric analyses were carried out using a Perkin Elmer Pyris 1 apparatus at $10^{\circ} \mathrm{C} \mathrm{min}^{-1}$ under air flow from ambient to $900^{\circ} \mathrm{C}$. Air flow was chosen because the processing steps (especially $\mathrm{MB}$ and compression moulding) are performed in the presence of air.

Microscopic observations were carried out at $15 \mathrm{kV}$ and a pressure of 0.9 Torr using FEI Quanta FEG ESEM (Hillsboro, Oregon, USA). Backscattered electron mode was chosen due to the chemical contrast between the PEEK phase (constituted of $\mathrm{C}, \mathrm{O}$ and $\mathrm{H}$ atoms) and elastomer phase (presence of $\mathrm{F}$ atoms for CFE). Elastomer particles appear in white. No metallization was needed.

Dynamic mechanical thermal properties were characterized in torsion mode by dynamic mechanical thermal analyser (model 2980; TA Instruments, New Castle, Delaware,
USA), with the single cantilever clamp on a rectangular sample with the dimension of $1 \mathrm{~mm}$ thickness, $17 \mathrm{~mm}$ length and $4 \mathrm{~mm}$ width. Temperature sweep measurements were carried out between $-100^{\circ} \mathrm{C}$ and $+130^{\circ} \mathrm{C}$ at $1 \mathrm{~Hz}$ with a programmed heating rate of $1^{\circ} \mathrm{C} \min ^{-1}$ using liquid nitrogen cooling accessory. In this experiment, shearing does not exceed $0.1 \%$, the dynamic mechanical testing device produces nearly perfect sinusoidal reference signal, without any harmonics (linear viscoelastic field). Storage modulus $\left(E^{\prime}\right)$ as well as $\tan \delta(\tan \delta)$, corresponding to the $E^{\prime \prime} / E^{\prime}$ ratio of the rubber phase, is considered. The relative damping ( $\eta$, in percentage) at peak of the PEEK-CFE composite is calculated considering a value of $100 \%$ for pure CFE at peak. In order to compare with Oberst test results, $\tan \delta$ and relative damping are also considered at $23^{\circ} \mathrm{C}$ (Oberst test temperature).

Modified Oberst method was also used for the measurement of the damping properties at room temperature $\left(23^{\circ} \mathrm{C}\right)$; the beam under test is simply screwed at the centre of the electrodynamic shaker with a threaded rod (Figure 1) $)^{2-24}$ and placed in an environmental chamber. Three accelerometers are used for the measurement: one to measure the random noise that causes the beam to vibrate and other two accelerometers to measure the response at the end of the beam. By measuring several resonances of the vibrating beam at various temperatures, the effects of frequency and temperature on the material can be determined. The $\mathrm{n} \mathrm{dB}$ method is used to measure the damping of the beam for each resonance mode $i$. It consists of measuring the resonance frequency $\left(f_{\text {res, } i}\right)$ and the gap $\left(\Delta f_{i}\right)$ between frequencies below and above the resonance frequency where the value of the frequency response function is $\mathrm{n} d B$ less than the value at resonance. The modal damping factor $\left(\eta_{\mathrm{i}}\right.$, in percentage) is computed using the following equation:

$$
\eta_{\mathrm{i}}=100 \times\left(\frac{1}{\sqrt{x^{2}-1}}\right) \frac{\Delta f_{\mathrm{i}}}{f_{\text {res }, \mathrm{i}}},
$$

where $x=10^{(n / 20)}$.

For more accuracy, the $\eta_{i}$ is determined as the mean of several values of $n$ between 0.5 and 3. Figure 2 shows 


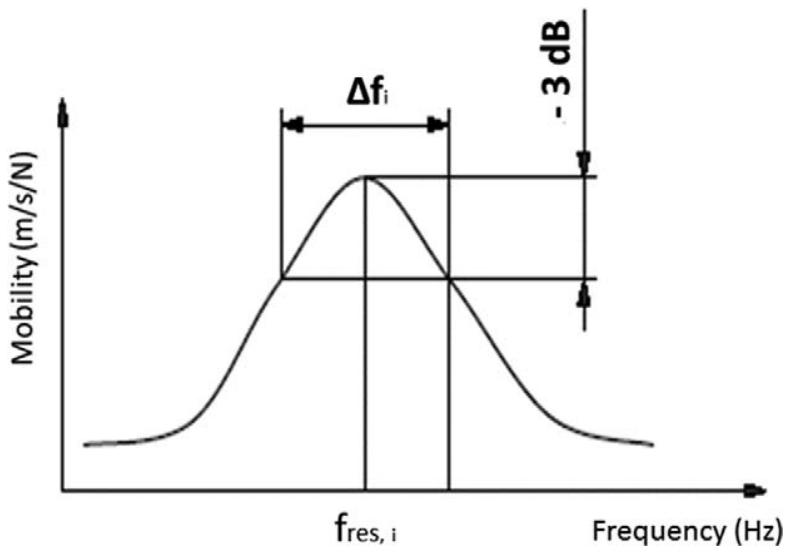

Figure 2. Determination of the $\tan \delta$ for modified Oberst test. $\tan \delta$ : damping factor.

Table I. Results of thermogravimetric analysis for PEEK and studied elastomers.

\begin{tabular}{lccc}
\hline Materials & $\begin{array}{c}\text { Temperature } \\
\text { for I wt\% mass } \\
\text { loss }\left({ }^{\circ} \mathrm{C}\right)\end{array}$ & $\begin{array}{c}\text { Temperature } \\
\text { for } 50 \text { wt\% mass } \\
\text { loss }\left({ }^{\circ} \mathrm{C}\right)\end{array}$ & $\begin{array}{c}\text { Mass loss } \\
\text { at } 370^{\circ} \mathrm{C} \\
(\mathrm{wt} \%)\end{array}$ \\
\hline PEEK & 567 & 814 & 99.7 \\
UFE & 285 & 482 & 97.5 \\
CFE & 414 & 530 & 99.5 \\
PDMS & 391 & 602 & 99.2 \\
\hline
\end{tabular}

PEEK: poly(ether ether ketone); UFE: uncross-linked fluoroelastomer; CFE: cross-linked fluoroelastomer; PDMS: polydimethylsiloxane.

an example for $n=3$. Two resonance frequencies corresponding to the second and third modes of resonance of the beam are studied: the second mode $(i=2)$ is localized near $288 \mathrm{~Hz}$ and corresponds to the flexion mode of the beam, the third mode $(i=3)$ is measured near $754 \mathrm{~Hz}$ and corresponds to the torsion mode of the beam. According to the ASTM E756 standard, the first mode $(i=1)$ is not measured because of its high amplitude, which could lead to a non-linear behaviour.

Three-point flexural tests were performed on specimens with a $1 \times 3 \mathrm{~mm}^{2}$ section and a distance between supports equal to $55 \mathrm{~mm}$. The cross-head speed was fixed at $1 \mathrm{~mm} \mathrm{~min}^{-1}$ and the maximal vertical displacement was $1.5 \mathrm{~mm}$. Three tests for each formulation were carried out using a Zwick testing machine (Germany).

Pyrolysis combustion flow calorimeter (PCFC) allows measuring some important fire properties of a material with only $2-4 \mathrm{mg}$ samples. The sample is pyrolysed in a nitrogen flow according to a heating ramp of $1^{\circ} \mathrm{C} \mathrm{s}^{-1}$ up to $750^{\circ} \mathrm{C}$. The gases from the decomposition of the material are extracted and sent into an oven at $900^{\circ} \mathrm{C}$ and mixed with oxygen in excess. ${ }^{25}$ The combustion of the gases is complete. An oxygen analyser measures the consumption of oxygen. According to Huggett's relation (1 kg of consumed

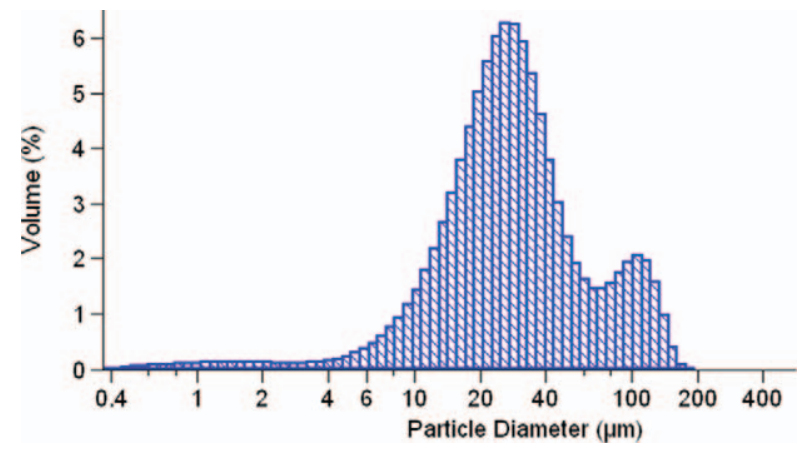

Figure 3. Particle's diameter distribution of CFE powder after grinding. CFE: cross-linked fluoroelastomer.

oxygen corresponds to $13.1 \mathrm{MJ}$ of released energy), ${ }^{26}$ the heat release rate is calculated. The peak heat release rate (pHRR) and the total heat release (THR) were considered to estimate the flammability of the blends. Uncertainties on pHRR and THR were estimated at approximately $10 \%$.

\section{Results}

\section{Elastomer phase selection}

The elastomer selection was based on two criteria. The first criterion is that the elastomer should be thermally stable at temperatures corresponding to the processing of PEEK. Table 1 presents the thermogravimetric data for the three elastomers (CFE, UFE and PDMS). The temperature at $1 \%$ weight loss was chosen to determine if the elastomers could be incorporated into PEEK at a processing temperature of $370^{\circ} \mathrm{C}$. Results show that UFE is not stable enough with a temperature at $1 \%$ weight loss of only $285^{\circ} \mathrm{C}$. At $370^{\circ} \mathrm{C}$, mass loss is already $2.5 \%$. On the contrary, CFE and PDMS could be good candidates with a mass loss at $370^{\circ} \mathrm{C}$ lower than $1 \%$.

The second criterion is that the elastomer phase should be easily ground into small particles. It is well known that the higher the $T_{\alpha}$, the harder the material at ambient temperature is and the smaller the particles after grinding will be. CFE has a high $T_{\alpha}$ (approximately $-20^{\circ} \mathrm{C}$ from differential scanning calorimeter (DSC) analysis at $10^{\circ} \mathrm{C} \mathrm{min}-1$ under nitrogen flow) and a high modulus with regard to the commonly used elastomers. On the contrary, the PDMS has a very low $T_{\alpha}$ (lower than $-100^{\circ} \mathrm{C}$, under limit of DSC). Therefore, despite its good thermal stability, PDMS has not been considered in this study because of its too low $T_{\alpha}$.

According to these results, CFE was considered as the best elastomer material to obtain micron-sized particles. After the micron-sized grinding, laser particle size granulometer measurements show a bimodal distribution of CFE particles with the main peak at the diameter of $30 \mu \mathrm{m}$ and a second peak at $100 \mu \mathrm{m}$ (Figure 3 ). This micronic size distribution of elastomer particles achieved the first of our three objectives previously discussed. Also, the CFE 
(a)

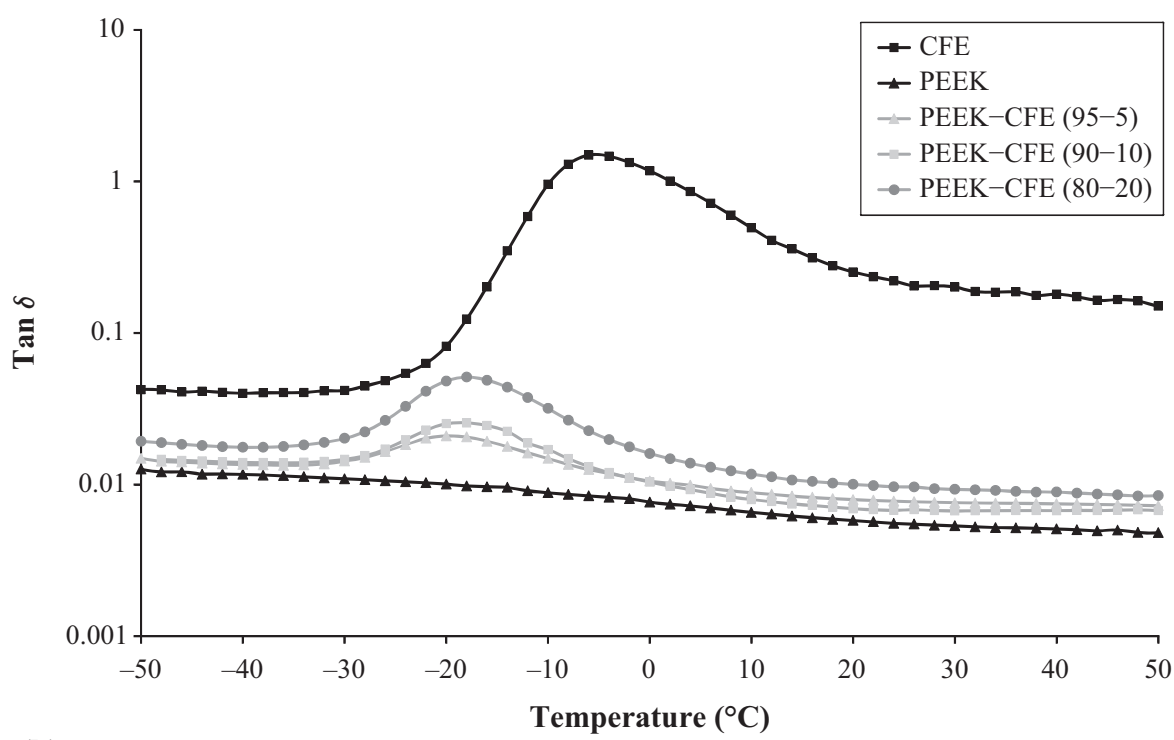

(b)

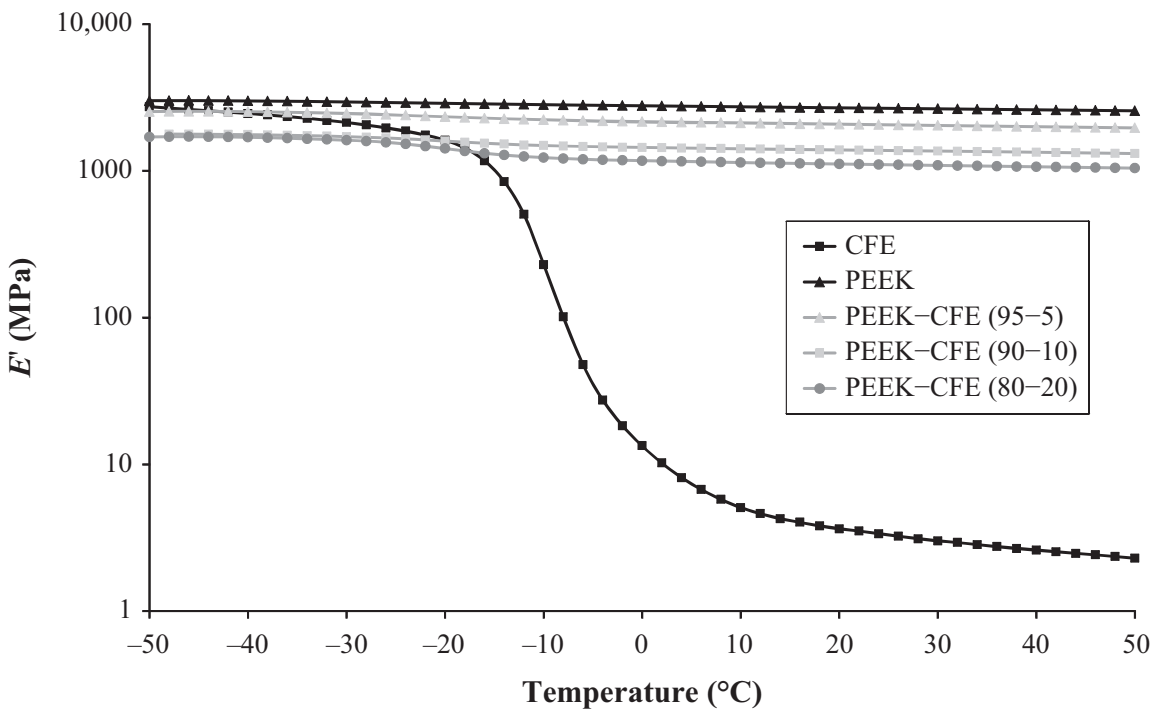

Figure 4. Dynamic mechanical spectra and temperature dependence of PEEK-CFE MB blends ( $\left.\mathrm{I} \mathrm{Hz}, 0.1 \%, \mathrm{I}^{\circ} \mathrm{C} \mathrm{min}^{-1}\right)$ : (a) $\tan \delta$ and (b) $E^{\prime}$. PEEK: poly(ether ether ketone); CFE: cross-linked fluoroelastomer; MB: melt blending; tan $\delta$ : damping factor; $E^{\prime}$ : storage modulus.

particles were incorporated into PEEK matrix via the MB and DB methods, respectively, as previously described.

\section{Dynamic mechanical thermal analysis of blends - Influence of the processing method}

Incorporation of the CFE powder in PEEK matrix is the most critical process. Even if the elastomer was carefully selected to minimize its degradation during the compound process, the choice of the process method is important to avoid any further degradation while ensuring a good dispersion of the CFE particles. Therefore, the DB and MB process methods will be compare in this section.
The $T_{\alpha} \mathrm{s}$ of the CFE elastomer, MB and DB of PEEKCFE blends (5, 10 and $20 \mathrm{wt} \%$ of CFE), are measured using DMTA. The curves of the MB and DB blends are described in Figures 4 and 5, respectively, and detailed in Table 2.

The CFE elastomer shows a $\tan \delta$ peak near $-5^{\circ} \mathrm{C}$ related to the $\alpha$ relaxation. The PEEK matrices (MB and DB) do not exhibit any relaxation peak in this temperature region. This peak related to the CFE relaxation is shifted to lower temperatures $\left(-17^{\circ} \mathrm{C}\right.$ to $\left.-20^{\circ} \mathrm{C}\right)$ in PEEK-CFE blends.

First, $E^{\prime}$ moduli values of MB PEEK and DB PEEK at $23^{\circ} \mathrm{C}$ are compared. A higher modulus is obtained for $\mathrm{MB}$ PEEK (2690 MPa) than DB PEEK (2237 MPa that 
(a)

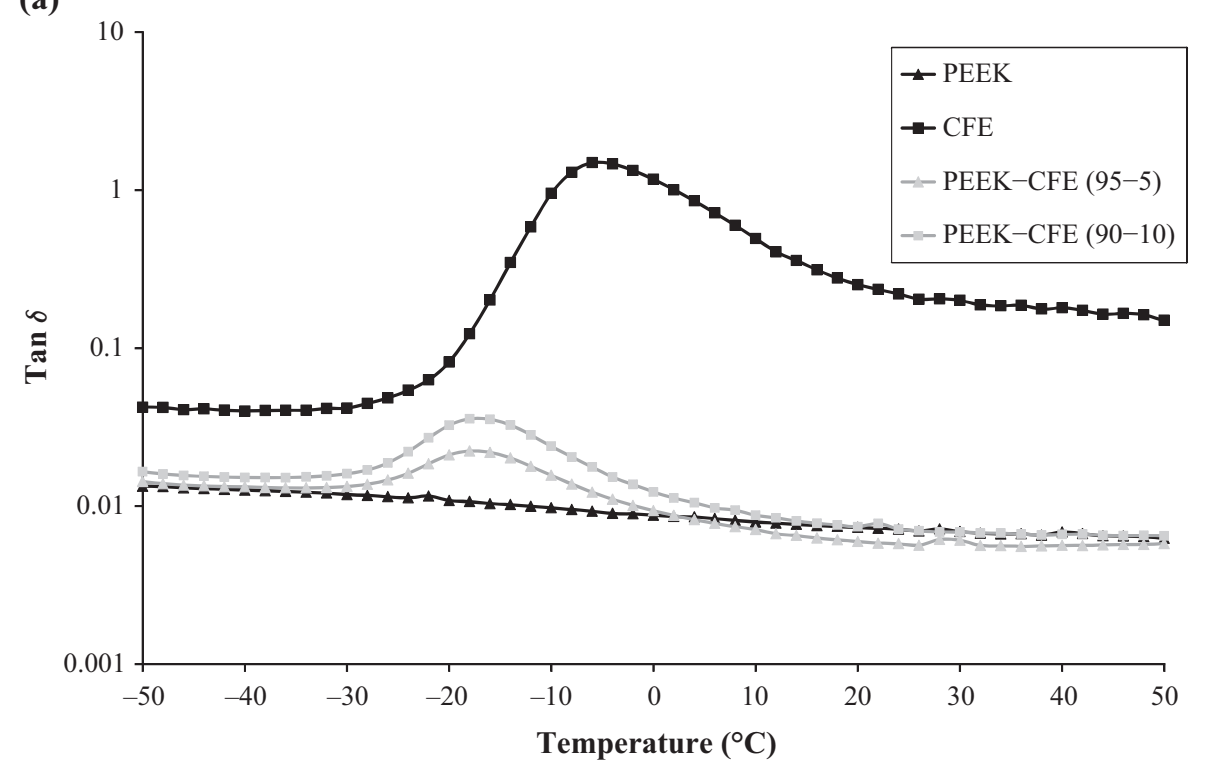

(b)

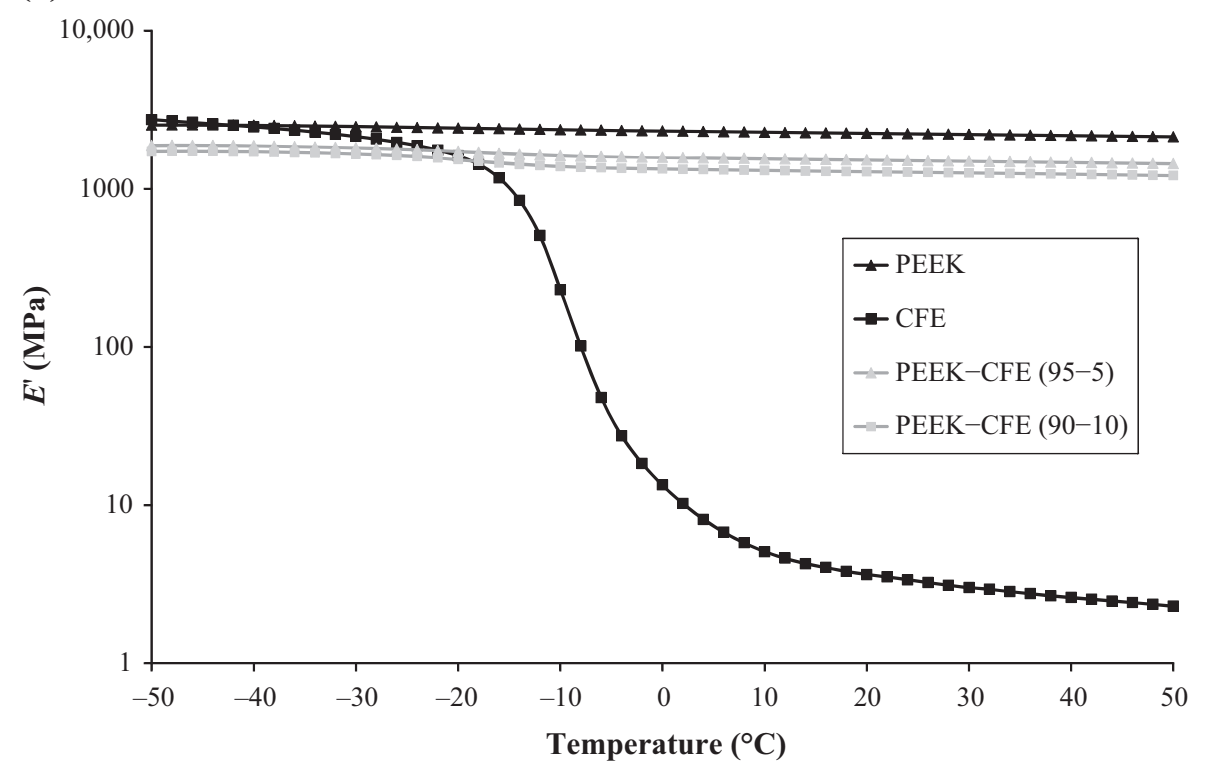

Figure 5. Dynamic mechanical spectra and temperature dependence of PEEK-CFE DB blends $\left(\mathrm{I} \mathrm{Hz}, 0.1 \%, 1{ }^{\circ} \mathrm{Cmin}^{-1}\right)$ : (a) $\tan \delta$ and (b) $E^{\prime}$. PEEK: poly(ether ether ketone); CFE: cross-linked fluoroelastomer; DB: dry blending; $\tan \delta$ : damping factor; $E^{\prime}$ : storage modulus.

corresponds to a loss of $17 \%$ ). Such a difference between both process methods is also confirmed for the PEEK-CFE blends. This result could be explained by the first step of compounding for MB blends, which probably reduced the trapping of air bubbles during the following compression moulding compared to DB blends. Note that for this reason, it was not possible to properly prepare DB PEEK sample containing $20 \mathrm{wt} \%$ of CFE. Finally, the MB method seems to be more efficient to preserve the intrinsic properties of the PEEK matrix. Nevertheless whatever the processing method, $E^{\prime}$ decreases quickly when increasing CFE content from $0 \mathrm{wt} \%$ to $20 \mathrm{wt} \%$ (almost $-50 \%$ for $\mathrm{MB}$ blends). This could be assigned to the very low $E^{\prime}$ of the CFE elastomer phase $\left(4 \mathrm{MPa}\right.$ at $\left.23^{\circ} \mathrm{C}\right)$ and to the lack of adhesion between both phases.

\section{Dynamic mechanical thermal analysis and modified Oberst test - Damping factor}

An improvement in the $\tan \delta$ of the as-prepared PEEK-CFE blends is the main objective of this work. Measurements of $\tan \delta$ are performed using two different methods such as DMTA and modified Oberst test. According to the previous results about processing method, MB was better than DB, 
Table 2. Results of DMTA for PEEK-CFE MB and DB blends.

\begin{tabular}{|c|c|c|c|c|c|c|c|}
\hline \multicolumn{2}{|l|}{ Material } & $\begin{array}{l}\mathrm{CFE}, T_{\alpha} \\
\left({ }^{\circ} \mathrm{C}\right)\end{array}$ & $\begin{array}{c}E^{\prime} \text { at } 23^{\circ} \mathrm{C} \\
(\mathrm{MPa})\end{array}$ & $\begin{array}{c}\text { Tan } \delta \text { value } \\
\text { at } 23^{\circ} \mathrm{C}\end{array}$ & $\begin{array}{c}\text { Relative damping } \\
\text { factor }(\eta) \text { at } 23^{\circ} \mathrm{C}(\%)\end{array}$ & $\begin{array}{c}\text { Tan } \delta \text { intensity } \\
\text { at peak }\end{array}$ & $\begin{array}{c}\text { Relative damping } \\
\text { at peak (\%) }\end{array}$ \\
\hline \multirow{5}{*}{$\begin{array}{l}\text { CFE } \\
\text { MB blends }\end{array}$} & & -5 & 4 & 0.252 & 100 & 1.49 & 100 \\
\hline & PEEK & NA & 2680 & 0.006 & 2.4 & 0.01 & 0.7 \\
\hline & $\begin{array}{c}\text { PEEK-CFE } \\
(95-5)\end{array}$ & -20 & 2070 & 0.008 & 3.2 & 0.021 & 1.3 \\
\hline & $\begin{array}{r}\text { PEEK-CFE } \\
(90-10)\end{array}$ & -19 & 1390 & 0.007 & 2.8 & 0.026 & 2.0 \\
\hline & $\begin{array}{r}\text { PEEK-CFE } \\
(80-20)\end{array}$ & -18 & 1115 & 0.010 & 4.0 & 0.051 & 3.3 \\
\hline \multirow[t]{3}{*}{ DB blends } & PEEK & NA & 2230 & 0.007 & 2.8 & 0.01 & 0.7 \\
\hline & $\begin{array}{c}\text { PEEK-CFE } \\
(95-5)\end{array}$ & -18 & 1515 & 0.006 & 2.4 & 0.022 & 1.3 \\
\hline & $\begin{array}{r}\text { PEEK-CFE } \\
(90-10)\end{array}$ & -17 & 1280 & 0.007 & 2.8 & 0.036 & 2.7 \\
\hline
\end{tabular}

DMTA: dynamic mechanical thermal analysis; PEEK: poly(ether ether ketone); CFE: cross-linked fluoroelastomer; MB: melt blending; DB: dry blending; $T_{\alpha}$ : glass transition temperature; $E^{\prime}$ : storage modulus; $\tan \delta$ : damping factor; $\eta$ : relative damping factor; NA: not available.

Table 3. Oberst measurements of $M B$ blends at $23^{\circ} \mathrm{C}$.

\begin{tabular}{lccrrr}
\hline & \multicolumn{2}{c}{ Flexion mode } & & \multicolumn{2}{c}{ Torsion mode } \\
\cline { 2 - 3 } MB blends & Resonance frequency $(\mathrm{Hz})$ & Relative damping $(\eta, \%)$ & Resonance frequency $(\mathrm{Hz})$ & Relative damping $(\eta, \%)$ \\
\hline PEEK & 288 & 2.0 & 754 & 1.7 \\
PEEK-CFE $(90-10)$ & 318 & 3.1 & 839 & 3.2 \\
PEEK-CFE $(80-20)$ & 279 & 3.4 & 724 & 3.6 \\
\hline
\end{tabular}

MB: melt blending; PEEK: poly(ether ether ketone); CFE: cross-linked fluoroelastomer; $\eta$ : relative damping factor.

so the comparison between DMTA and modified Oberst test is discussed only for MB blends.

For DMTA, the relative damping is calculated from the $\tan \delta$ values at peak (corresponding to the CFE $\alpha$ relaxation) and at $23^{\circ} \mathrm{C}$ (in order to compare Oberst test values) (Table 2). Remember that $100 \%$ value corresponds to the damping of pure CFE. A slight (quasi-negligible) increase in relative damping at peak from $0.7 \%$ to $3.3 \%$ is obtained when $20 \%$ of the CFE is introduced in PEEK (DB and MB blends). At $23^{\circ} \mathrm{C}$, the relative damping of $\mathrm{DB}$ and $\mathrm{MB}$ blends is slightly higher (2-4\%) but remains very low.

For modified Oberst test, the frequency resonance and $\eta$ of MB blends are measured according to Equation (1). The results of the modified Oberst test are summarized in Table 3.

For MB PEEK matrix, the values of $\tan \delta \mathrm{s}$ are $2.0 \%$ for the flexion mode and $1.7 \%$ for the torsion mode, respectively, compared to $2.4 \%$ obtained from DMTA experiments at the same temperature $\left(23^{\circ} \mathrm{C}\right)$. The presence of $20 \mathrm{wt} \%$ of CFE within MB PEEK increases $\tan \delta$ s from $2.0 \%$ to $3.4 \%$ and from $1.7 \%$ to $3.6 \%$ for flexural and torsion modes, respectively. This result is in agreement with DMTA experiments, which also show an increase in the relative damping at $23^{\circ} \mathrm{C}$ from $2.4 \%$ to $4.0 \%$ (Table 2) when the CFE content increases from $0 \%$ to $20 \%$ within PEEK as concerns MB blends.
Whatever the method used for the relative damping measurement and the samples, the same tendency is observed and a good agreement could be found between DMTA and Oberst test damping values at $23^{\circ} \mathrm{C}$ (Figure 6). The increase in relative damping is proportional to the CFE content in the case of MB blends. Nevertheless, in all cases, the relative damping remains very low despite the large intrinsic damping of the elastomer phase $(<5 \%$ even at $20 \mathrm{wt} \%$ of CFE). According to Figure 6, the experimental values of $\tan \delta$ s of blends are well below those calculated according to the linear rule of mixtures. The lack of adhesion between PEEK and CFE particles could probably explain such limited improvement.

Despite these poor performances, further characterizations were carried out on MB blends. According to the poor mechanical properties of DB PEEK matrix and the associated composites, this incorporation method is given up.

\section{Static mechanical properties - Flexural modulus}

Flexural modulus is an important property in the point of view of the desired application. Figure 7 shows the flexural modulus of PEEK-CFE MB blends. Flexural modulus of PEEK is higher than $3500 \mathrm{MPa}$, which is in agreement with literature. ${ }^{27} \mathrm{~A}$ quasi-linear decrease in flexural modulus 


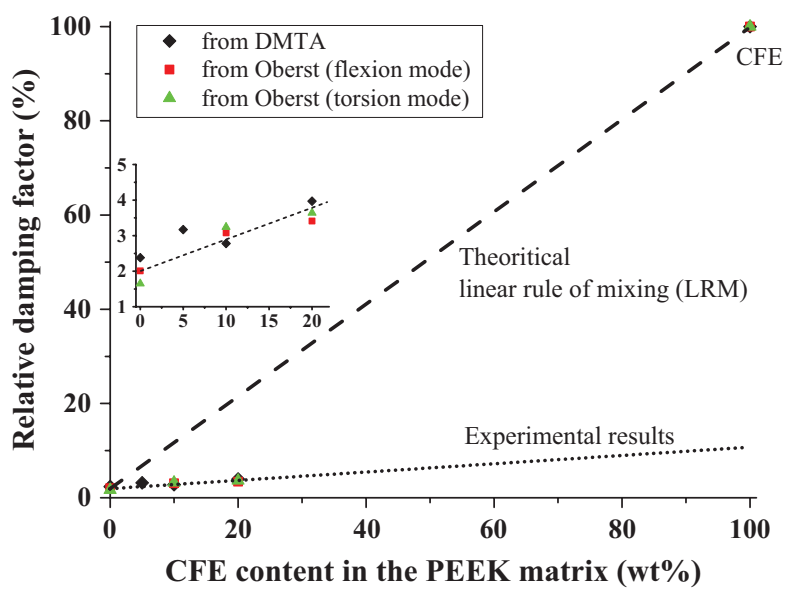

Figure 6. Relation between CFE content and relative damping for $M B$ blends (the dashed and dotted lines are only done as eye guidelines). CFE: cross-linked fluoroelastomer; MB: melt blending.

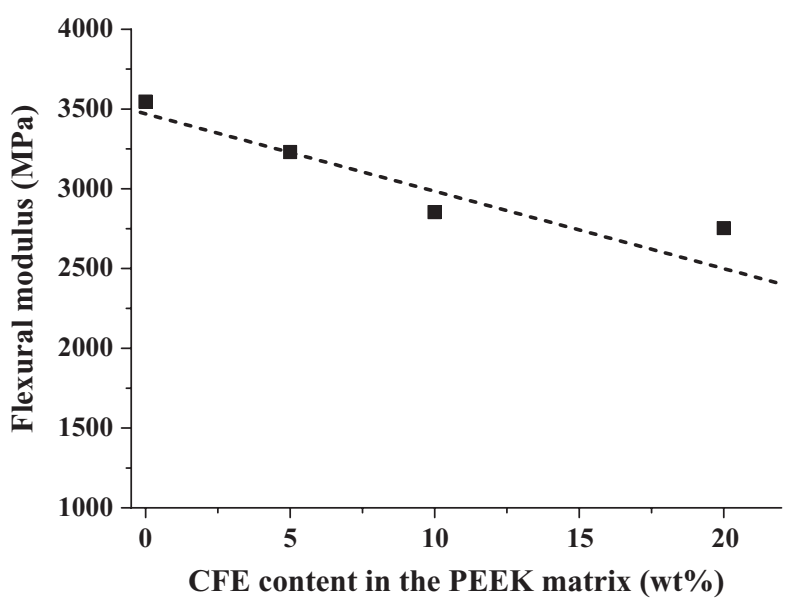

Figure 7. Flexural modulus of PEEK-CFE MB blends. PEEK: poly(ether ether ketone); CFE: cross-linked fluoroelastomer; MB: melt blending.

could be noticed when increasing the CFE content. The decrease of about $-22 \%$ with $20 \mathrm{wt} \%$ of CFE in PEEK. Two main reasons may explain this result. One of them is that the interfacial adhesion between PEEK and CFE particles is very low as it can be seen on scanning electron microscopy (SEM) micrographs (Figure 8). The second reason is the large difference between CFE and PEEK moduli limiting the stress transfer from the matrix to the particles (even if interfacial adhesion was improved). Similar results were found for PE-GTR blends. ${ }^{10}$

\section{SEM observations}

Microscopic observations of PEEK-CFE MB blends before compression moulding were carried out to understand the obtained poor mechanical properties. SEM photographs are presented in Figure 8. White CFE particles could be clearly

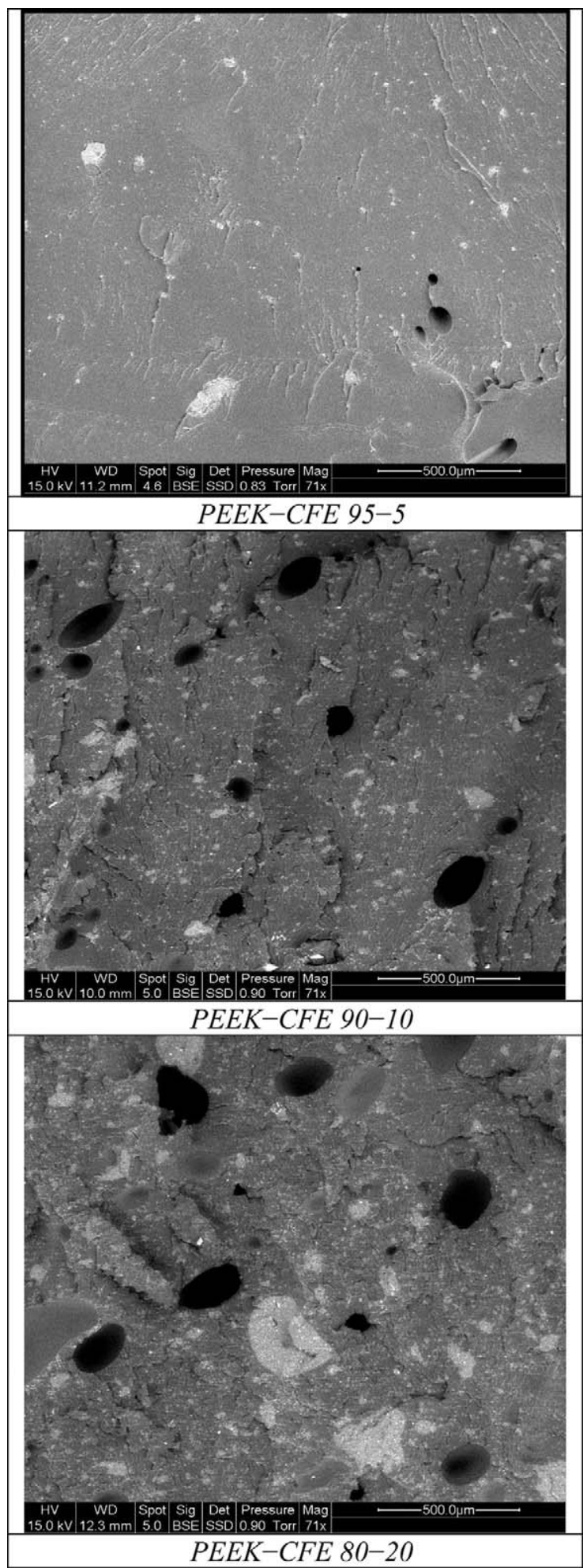

Figure 8. SEM observations of fractured MB blend samples before compression moulding. SEM: scanning electron microscopy; MB: melt blending.

observed in the PEEK matrix. The black domains correspond to the ejected CFE particles during sample preparation and/or air bubbles. Bubbles are due to the air trapped 


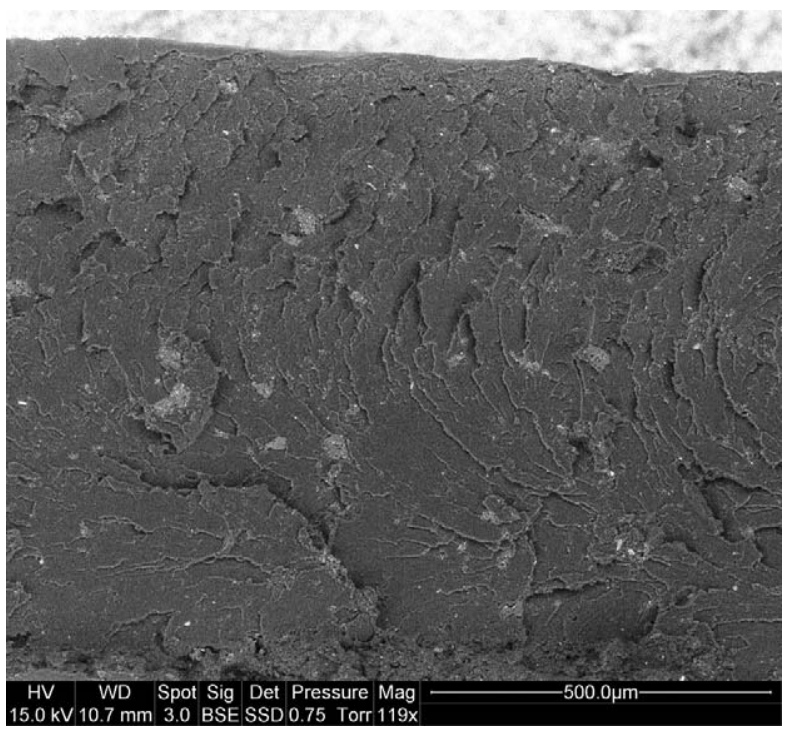

Figure 9. SEM observations of PEEK-CFE (95-5) MB blends after compression moulding. SEM: scanning electron microscopy; PEEK: poly(ether ether ketone); CFE: crosslinked fluoroelastomer; MB: melt blending.

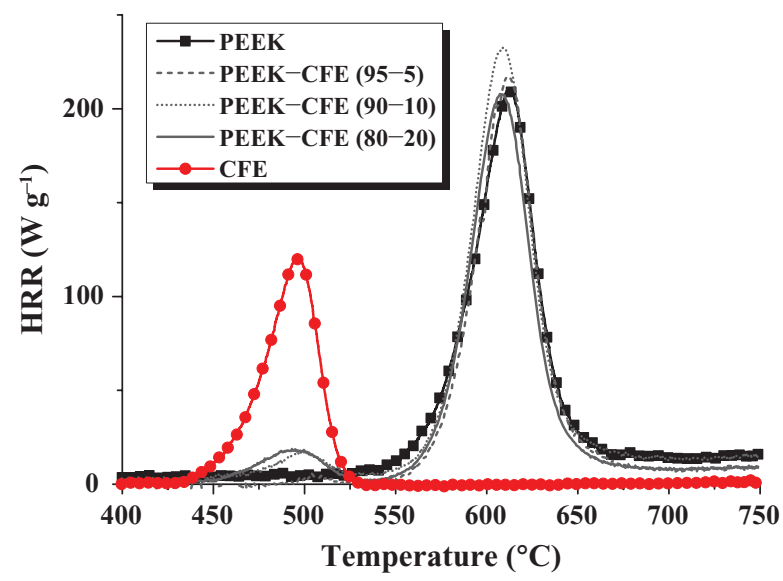

Figure I0. HRR versus temperature (PCFC curves) for $M B$ blends. HRR: heat release rate; PCFC: pyrolysis combustion flow calorimeter; MB: melt blending.

into the highly viscous matrix during MB. Considering this result, compression moulding was carried out at a higher temperature $\left(400^{\circ} \mathrm{C}\right)$ and with several cycles of pressure depression to remove air carefully. Figure 9 shows the PEEK-CFE (95-5) MB blends after compression moulding. No air bubbles could be found.

In all cases, CFE particles are well dispersed. Many particles have a diameter close to $30 \mu \mathrm{m}$, but some bigger particles have a diameter close to $100 \mu \mathrm{m}$. This is in agreement with the results of laser particle size analyser (Figure 3). Once cross-linked, the CFE particles could not be broken during processing. The smooth and clear boundaries between the CFE particles and PEEK matrix
Table 4. PCFC results for PEEK, CFE and MB blends.

\begin{tabular}{lccc}
\hline Material & $\begin{array}{c}\text { Temperature of } \\
\text { main peak }\left({ }^{\circ} \mathrm{C}\right)\end{array}$ & $\begin{array}{c}\text { Main PHRR } \\
\left(\mathrm{W} \mathrm{g}^{-1}\right)\end{array}$ & $\begin{array}{c}\text { THR } \\
\left(\mathrm{k} \mathrm{g} \mathrm{g}^{-1}\right)\end{array}$ \\
\hline PEEK & 613 & 200 & 8.4 \\
PEEK-CFE (95-5) & 613 & 211 & 8.0 \\
PEEK-CFE (90-10) & 607 & 221 & 8.6 \\
PEEK-CFE (80-20) & 608 & 201 & 8.1 \\
CFE & 497 & 121 & 4.9 \\
\hline
\end{tabular}

PCFC: pyrolysis combustion flow calorimeter; PEEK: poly(ether ether ketone); CFE: cross-linked fluoroelastomer; MB: melt blending; pHRR: peak heat release rate; THR: total heat release.

are also an indication of the absence of entanglements between macromolecules of both polymers.

According to these SEM observations, good dispersion and micron-sized CFE particles were observed into PEEK matrix. But poor interfacial adhesion between CFE and PEEK is the most prominent characteristic leading to damaged mechanical properties of PEEK-CFE composites. Bubbles at high CFE contents could also contribute to these poor properties.

\section{Flammability}

The PCFC curves are shown in Figure 10. Results are summarized in Table 4. PEEK is well known for its outstanding fire behaviour and exhibits a V0 ranking in vertical UL94 test (V0 is the best ranking). It degrades at high temperature with relatively low heat release rate and forms a high amount of char. The CFE is a fluoroelastomer and then its flammability properties are better than those of PEEK (pHRR and THR are $121 \mathrm{~W} \mathrm{~g}^{-1}$ and $4.9 \mathrm{~kJ} \mathrm{~g}^{-1}$, respectively, for CFE and $200 \mathrm{~W} \mathrm{~g}^{-1}$ and $8.4 \mathrm{~kJ} \mathrm{~g}^{-1}$, respectively, for PEEK). On the other hand, the $\mathrm{CFE}$ degrades at a lower temperature than PEEK $\left(497^{\circ} \mathrm{C}\right.$ vs. $613^{\circ} \mathrm{C}$ ). The MB blend curves present two peaks corresponding to both polymers. The incorporation of 5-20 wt $\%$ CFE does not lead to a significant increase in pHRR and THR but the presence of a small peak at $500^{\circ} \mathrm{C}$ could degrade the fire behaviour of the material.

The PCFC was chosen because it allows estimating the fire behaviour of a very small sample $(2-4 \mathrm{mg})$. Nevertheless, this method is not used for standardization, for example, in aeronautic field. Therefore, estimating the ranking of a material in another fire test from PCFC results would be useful. To find the correlations between different fire tests is still a difficult challenge. The PCFC could not be well correlated to cone calorimeter test because some phenomena like barrier effect are not efficient for $2-4 \mathrm{mg}$ samples. ${ }^{28}$ But other studies have established statistical correlations between PCFC and other tests, like limiting oxygen index or UL94, which are the most common simple tests used in industrial field. ${ }^{29}$ The authors showed that a material with a heat release capacity (HRC) lower than about $250 \mathrm{~J} \mathrm{~g}^{-1} \mathrm{~K}^{-1}$ should be V0 in UL94 test with 
high probability. ${ }^{29} \mathrm{HRC}$ is equal to the sum of pHRR divided by the heating rate. In the present case, HRC is 200-220 $\mathrm{J} \mathrm{g}^{-1} \mathrm{~K}^{-1}$ for all the MB blends. In the same article, another statistical study showed that the probability of burning in UL94 test is $0-0.2$ for materials with a THR lower than $10 \mathrm{~kJ} \mathrm{~g}^{-1}$ and with a HRC of $200 \mathrm{~J} \mathrm{~g}^{-1} \mathrm{~K}^{-1.29}$ Considering this study performed on more than 100 polymers and composites, the MB blends should be classified as V0 in vertical UL94 test even if the incorporation of the CFE decreases the thermal stability of the MB blends.

\section{Conclusions}

The incorporation of elastomer particles into a PEEK matrix was described with a particular emphasis on the choice of rubber material and processing conditions. Suitable conditions were determined to avoid the degradation of the elastomer phase during grinding and blending, so that a CFE was chosen. Concerning the two incorporation methods, it was shown that DB method was not relevant and degrades intrinsic properties of the PEEK matrix. Consequently, the study was then focused on MB blends. Mechanical properties of various PEEK-CFE blends (contents included in the range of 5-20 wt \%) were measured at low deformation levels. A linear decrease in flexural modulus with the increase in CFE content was observed. Damping properties were estimated according to the following two methods, that is, classical DMTA measurements and more original Oberst tests. The results of both methods are in agreement and show a negligible increase in the relative damping with the incorporation of CFE (less than $5 \%$ with $20 \mathrm{wt} \%$ of CFE at room temperature according to both tests). The PCFC analyses show thermal stability of the blends is lower than that of pure PEEK, but the materials should not be downgraded in UL94 test.

Poor interfacial adhesion is proposed as the main reason of these results. Nevertheless, while elastomer particles could be MB with PEEK without significant degradation, further investigations should improve the properties of our hot melt PEEKCFE blend. In this way, grinding at cryogenic temperatures (to decrease the particles size) and surface treatment of elastomer particles are proposed to make possible this blend as a good alternative to conventional sandwich composite.

\section{Funding}

This research received no specific grant from any funding agency in the public, commercial, or not-for-profit sectors.

\section{References}

1. Thompson DJ. A continuous damped vibration absorber to reduce broad-band wave propagation in beams. J Sound Vib 2008; 311: 824-842.

2. Hazard L and Bouillard P. Structural dynamics of viscoelastic sandwich plates by the partition of unity finite element method. Comput Methods Appl Mech Eng 2007; 196: 4101-4116.
3. Alvelid M and Enelund M. Modelling of constrained thin rubber layer with emphasis on damping. J Sound Vib 2007; 300: 662-675.

4. Kari L, Lindgren K, Feng L, et al. Constrained polymer layers to reduce noise: reality or fiction? - an experimental inquiry into their effectiveness. Polym Test 2002; 21: 949-958.

5. Kwak GH, Inoue K, Tominaga Y, et al. Characterization of the vibrational damping loss factor and viscoelastic properties of ethylene-propylene rubbers reinforced with microscale fillers. J Appl Polym Sci 2001; 82: 3058-3066.

6. Assarar M, El Mahi A and Berthelot J-M. Damping analysis of sandwich composite materials. J Compos Mater 2009; 43: 1461-1485.

7. Olcott DD, Rotz CA and Eastman PF. Improved vibration damping in composite structures using "zig-zag" fibers and embedded viscoelastic damping layers. In: Proceedings of the 1993 38th Int. SAMPE Symp. and Exhib., Advanced Materials: Performance through Technology Insertion, Anaheim, CA, Vol. 38, no. 2, 1993, pp. 1357-1370.

8. SMAC. Available at: http://www.smac-sas.com/ (accessed 30 April 2014).

9. Drobny JG. Handbook of thermoplastic elastomers. Elsevier; 2007, doi:10.1016/B978-081551549-4.50016-5.

10. Sonnier R, Leroy E, Clerc L, et al. Compatibilizing thermoplastic/ground tyre rubber powder blends: efficiency and limits. Polym Test 2008; 27: 901-907.

11. Wagenknecht U, Wiessner S, Heinrich G, et al. Effects of interface reactions in compatibilised ground tyre rubber polypropylene elastomeric alloys. Plast Rubber Compos 2006; 35:393-400.

12. Hassan MM, Badway NA, Gamal AM, et al. Studies on mechanical, thermal and morphological properties of irradiated recycled polyamide and waste rubber powder blends. Nucl Instrum Methods Phys Res B: Beam Interact Mater Atoms 2010; 268: 1427-1434.

13. Barth BP. Mixtures of polyarylene polyethers and vinylidene fluoride-hexafluoropropene copolymers, 1968.

14. Petersen M. Blends of poly(arylene ether ketones) and tetrafluoroethylene copolymers, 1988.

15. Rubber and PEEK polymer-based composite developed for sealing applications. Seal Technol 2011; 2011: 2-3.

16. Dutta NK and Tripathy DK. Strain dependent dynamic mechanical properties of black loaded vulcanizates. Kaut Gummi Kunstst 1989; 42: 665-671.

17. Hagen R, Salmén L and Stenberg B. Effects of the type of crosslink on viscoelastic properties of natural rubber. J Polym Sci B: Polym Phys 1996; 34: 1997-2006.

18. Aprem AS, Joseph K, Laxminarayanan R, et al. Physical, mechanical, and viscoelastic properties of natural rubber vulcanizates cured with new binary accelerator system. $J$ Appl Polym Sci 2003; 87: 2193-2203.

19. Ramier J. Comportement mécanique d'élastomères chargés, influence de l'adhésion charge-polymère, influence de la morphologie, 2004. 
20. Sosson F, Belec L, Chailan J-F, et al. Highlight of a compensation effect between filler morphology and loading on dynamic properties of filled rubbers. J Appl Polym Sci 2010; 117: 2715-2723.

21. ISO 16940. Modified Oberst normalised procedure.

22. ASTM E756-04. Standard test method for measuring vibration-damping properties, 1-13.

23. AFNOR. Verre dans la construction _ Vitrages et isolation aux bruits aériens Mesurage de l'impédance mécanique du verre feuilleté 2008; ISO 16940.

24. Wojtowicki J-L, Jaouen L and Panneton R. New approach for the measurement of damping properties of materials using the Oberst beam. Rev Sci Instrum 2004; 75: 2569.
25. Lyon RE and Walters RN. Pyrolysis combustion flow calorimetry. J Anal Appl Pyrol 2004; 71: 27-46.

26. Huggett $C$. Estimation of rate of heat release by means of oxygen consumption measurements. Fire Mater 1980; 4: 61-65.

27. Mark J. Polymer data handbook. New York, NY: Oxford University Press, 1999.

28. Sonnier R, Ferry L, Longuet C, et al. Combining cone calorimeter and PCFC to determine the mode of action of flame-retardant additives. Polym Adv Technol 2011; 22: 1091-1099.

29. Lyon RE, Takemori MT, Safronava N, et al. A molecular basis for polymer flammability. Polymer 2009; 50: 2608-2617. 